\title{
Understanding the Impacts of Climate Change on Health to Better Manage Adaptation Action
}

\author{
Clare Heaviside ${ }^{1,2,3}$ (D) \\ 1 Environmental Change Institute, University of Oxford, South Parks Road, Oxford OX1 3QY, UK; \\ clare.heaviside@ouce.ox.ac.uk \\ 2 School of Geography Earth and Environmental Sciences, University of Birmingham, \\ Birmingham B15 2TT, UK \\ 3 Department of Social and Environmental Health Research, London School of Hygiene \& Tropical Medicine, \\ London WC1E 7HT, UK
}

Received: 28 February 2019; Accepted: 2 March 2019; Published: 5 March 2019

check for updates

\section{Background}

The atmospheric and climate research communities have made significant advances in recent decades in gathering and understanding the scientific evidence supporting the concept of anthropogenic climate change. The IPCC (Intergovernmental Panel on Climate Change) has been instrumental in synthesizing the latest research on the state of our climate and projected future changes [1], as well as reporting on the impacts of climate change [2,3]. The urgency and scale of the challenge of our changing climate is widely accepted, and reflected by several landmark international agreements [4]. Of particular significance was the Paris Agreement of 2016; an international call for action to reduce global temperature rises to $2{ }^{\circ} \mathrm{C}$, and preferably below $1.5^{\circ} \mathrm{C}$ [5].

Already the human cost of climate change is being realised through the increasing frequency of floods, heatwaves, storms and forest fires leading to loss of life and injury; there are also long term health impacts following extreme events such as trauma, chronic illness, and mental health effects as a result of displacement [2]. Climate change also affects health through changes in ambient temperatures, air pollution, and changes to local environments which can introduce new disease vectors [3,6-8]. Specific risks will vary for different climatic zones, and impacts for each population group will be felt differently, depending on vulnerability due to social, economic and demographic factors.

The steady growth in the body of research into climate change impacts and adaptation topics has partly been driven by the acknowledgement that until we understand the impacts of various degrees of warming, there is a lack of momentum to aim for a specific target. Quantifying societal impacts can provide incentives to policymakers and others to limit emissions of greenhouse gases and implement adaptation measures, because the devastating effects if we do not take action, become more apparent. It is therefore important that there is continued effort to characterize and quantify the impacts of climate change, particularly at local and regional levels, since this is what will drive improvements in climate change mitigation and adaptation policy [9].

Cross-disciplinary working in the fields of climate change and health allows us to better understand and report the relationships between the environment and health. We need to strengthen the evidence base for impacts, not only of changes to climate, but of interventions which may be put in place to either mitigate against climate change or to adapt to it. Quantification of the human costs of climate change is particularly important when we seek to influence policymakers and the public of the overwhelming need to both reduce the extent of climate change, and to rapidly adapt to changes to which we are already committed due to greenhouse gases emitted since the start of the industrial revolution. 
The aim of this Special Issue on The Health Impacts of Climate Change is to explore impacts of climate change and adaptation to it, and to promote inter-disciplinary working in the field of atmospheric and health sciences. This type of research enables robust strengthening of the evidence base for climate change impacts on health, which motivates policy level action for mitigation; allows estimation of potential impacts to aid planning and response; and helps assess the most effective methods of adaptation to reduce impacts in future.

This collection of articles draws from a number of international authors and includes original research articles and comprehensive reviews. Summaries of the papers comprising the special issue are given below, categorized into three broad areas: (1) Understanding the complex relationships between the environment and health; (2) Quantification of the health impacts of temperature changes; and (3) Embedding scientific evidence into adaptation practice.

\section{Understanding the Complex Relationships between the Environment and Health}

The relationship between meteorological variables and health outcomes using empirical methods has been recognized for several decades. More recently, attempts have been made to estimate or project how climate change may affect health in future, and to a greater or lesser extent, these studies have attempted to include modifying factors such as changes in demographics, population health and adaptation measures. Most research has focused on the direct impact of changes in climate, rather than the more indirect pathways through which changes in the environment can have an impact on health, for example, through environmental degradation, and socio-economic changes driven by climate change. There is also significantly more research in high income countries than medium and low-income countries, where data can be sparse $[10,11]$.

Fleming et al. [12] review some of the broad health effects of environmental change, particularly changes to the natural environment, and with reference to infectious and vector-borne diseases, and aeroallergen exposure. Also covered is a growing body of research which aims to quantify the benefits (to health, wellbeing and the economy) as well as the risks of human interactions with the natural environment, focusing mainly on the UK. Benefits to physical and mental health come from interacting with the natural environment, e.g., residing in areas with more greenspace, and visiting parks and recreation areas. The review highlights research which shows that there are differences between the effects of different environments (e.g., coastal, rural, urban) on mental health and exercise capacity [12]. Health-economic assessments of co-benefits to health and the economy from climate change mitigation and adaptation measures are essential to underpin cost-benefit analyses for policy makers.

Water related or water-borne diseases have devastating impacts on health worldwide, especially in developing countries. The relationship between these types of infectious disease and climate variability and change is reviewed by Nichols et al. [13], who highlight that climate change poses a potential risk associated with the incidence of cholera, typhoid, dysentery, leptospirosis, diarrhoeal diseases and harmful algal blooms [13]. Although there are clearly direct links between weather conditions and infectious disease risk, the indirect effects of climate change which may drive population movements and conflict are also likely to affect the incidence of many water related infectious diseases.

Two papers in this special issue address the links between large scale climate dynamics and health: specifically the El Nino Southern Oscillation (ENSO) and the North Atlantic Oscillation (NAO) which are both important modes of global climate variability $[14,15]$. The first provides an overview of the characteristics and impacts of ENSO, a major driver of inter-annual climate variability, and gives an up to date review of literature seeking to understand the associations between various ENSO indices and health impacts. ENSO may modify parameters such as rainfall, wind, air and sea temperatures in different geographic regions, which has consequences for temperature-related health effects, flooding, and the spread of infectious diseases such as malaria and dengue. One conclusion drawn is that a purely statistical framework is not always sufficient to understand the complex societal impacts of a phenomenon such as ENSO, and that caution should be applied when choosing an ENSO index for impact studies [14]. 
The second paper looking at atmospheric dynamics specifically investigates the connection between phases of the North Atlantic Oscillation (NAO), the dominant mode of atmospheric variability in the northern hemisphere, and ambulance call outs for elevated blood pressure [15]. The analysis was based on a regression of daily emergency ambulance calls in Lithuania for hypertension, and NAO Indices, adjusting for season, weather and air pollutant confounders. The relationship between high blood pressure and the NAO is likely to be associated with the low temperatures occurring during anticyclonic conditions, and increased emergency ambulance calls for elevated arterial blood pressure were found for both the positive and negative values of the NAO index, varying depending on season [15].

\section{Quantification of the Health Impacts of Temperature Changes}

The environment, weather and climate all have profound impacts on health, either through direct associations or through less obvious pathways, which can make quantification difficult. However, one of the most widely studied, and therefore the most well understood impacts of climate change on health is through direct changes in temperature, which can increase the risk of illness and hospitalization, or lead to premature mortality.

Kinney [16] presents a comprehensive, up to date review of the relationship between temperature and health impacts (from both heat and cold), from morbidity to mortality, in different global regions, as well as how these relationships have changed over time. Heat-mortality relationships have been shown to vary by geographic region and population group, but less well studied is how relationships may have changed over time. Kinney reviews the emerging literature to try to answer this question, and gives guidance on taking account of trends over time and space when projecting future impacts of climate change and the associated change in temperature [16].

There are further research papers addressing the effects of temperatures on health in this issue, including analyses on heatwaves and cold spells, and reduced productivity in relation to heat. Two of the papers in this special issue focus on the incidence of heatwaves [17] and cold spells [18] over a 50 year period (1966-2015) in the city of Poznan, Poland. The authors highlight how the diversity of land type is reflected by diverse thermal conditions across the city compared with the reference monitoring stations, and the increased frequency of heatwave and reduced frequency of cold spells over the period studied.

Muthers et al. [19] pinpoint specific heatwave events which occurred during the years of 2003 and 2015, and estimate the resulting heat-related mortality in South West Germany. Results showed daily mortality anomalies reached $+70 \%$ and $+56 \%$ during the summers of 2003 and 2015, respectively, and climate projections indicate the increasing probability of comparable heatwaves occurring every second summer in the near future (2021-2050s) [19].

As well as leading to premature mortality, high temperatures and heat stress can also be detrimental to productivity. This can be a difficult effect to quantify, and is a subject tackled by Dear [20]. Here, a modelling approach is adopted which aims to build on existing evidence and which can express productivity as a function of environmental heat, and considers variations between individual workers [20].

\section{Embedding Scientific Evidence into Adaptation Practice}

The final set of papers address possible adaptation and planning responses to the effects of climate change on health. For example, Orru et al. [21] argue that resilience in the face of climate change is necessarily driven by the functioning of health systems and the drivers which shape system effectiveness. The authors use an example of the Estonian health system, and find that the health impacts of climate change have not been mainstreamed into policy. There is currently an opportunity to combine information from various sources, on health systems, the environment and vulnerability, although this prospect has not been embraced fully due to various reasons, including lack of knowledge and understanding of extreme events and how to incorporate projected risks into policy, and unclear 
division of responsibility [21]. Careful resource planning is an important consideration for the health sector, especially in the face of an increased risk of extreme weather events. Papadakis et al. [22] analyse emergency ambulance calls during episodes of extreme temperatures in London, UK, and propose a statistical physics based method to more accurately estimate the true burden on the health system during these events, which has potential for the ambulance service to more efficiently manage resources [22].

In the Netherlands, the issue of the urgent need for additional housing within existing urban boundaries is addressed [23]. Koopmans et al. test a range of urban planning strategies and their potential impacts on heat stress up to 2050, in the Hague. In particular, the impact of urban fabric on the urban heat island intensity is considered, and it was found that increasing vegetation fraction is a critical parameter in reducing excess heat stress in denser neighbourhoods, even if high rise buildings are preserved. However, the effects of climate change are thought to be likely to overwhelm the effects of increased urban densification in future [23].

Taylor et al. [24] use building models to quantify indoor temperatures in different dwelling types, and investigate the potential impacts on heat-related mortality of a range of adaptation measures under future climate change scenarios. Adaptation measures included mitigation of heat, improved energy efficiency, and changes in occupant behaviour, finding that external shutters provided the greatest benefits in terms of reducing heat-related mortality (by around $40 \%$ ) and closed windows led to increased risk (of 29-64\%) [24]. The authors highlight the importance of appropriate building design to both save energy and reduce heat-related mortality, especially for dwelling types associated with heat-vulnerable populations.

\section{Discussion}

The research published in this special issue has touched on three broad areas: (1) a discussion of the complex interactions between our environment and health, including the influence of large-scale dynamical systems; (2) quantitative estimates of the impacts of climate change in health, particularly through changes in temperature; and (3) an examination of the potential for adaptation and mitigation methods to modify the risks to health from climate change. Clearly, multi-disciplinary research on all these areas can help move us forward in understanding the risks and minimising the impacts of climate change on health.

There are more challenges for the future, however. Any mitigation and adaptation action on climate change needs to follow a 'co-benefits' approach to maximise public health benefits at the same time as reducing health risks [25]. Economic costs of impacts based on a lack of action should be calculated, but to motivate policy decisions, economic benefits from taking mitigation or adaptation action are essential. A multi-disciplinary approach is essential to minimise the risk of unintended consequences that are a danger when considering impacts in isolation.

As this inter-disciplinary field of research grows, and climate impacts on health outcomes become more widely understood, the scientific community has an opportunity to instigate positive societal changes, but further thought should be given as to how and where to take action in order to maximise health benefits. To reduce health inequalities, resources need to be applied to the populations mostly at risk, and where benefits are likely to be felt most widely. Historically, the balance of research has disproportionately focused on high income countries, where risks are generally lower [26]. The rollout of global research programmes on environment and health which embrace innovative approaches has the potential to shift this balance towards lower and middle income countries, and to focus attention where it is most needed [27].

Acknowledgments: We are grateful to all authors and reviewers who contributed to this special issue. C.H. is funded by NERC (grant number NE/R01440X/1).

Conflicts of Interest: The authors declare no conflict of interest. 


\section{References}

1. Stocker, T.F.D.; Qin, G.-K.; Plattner, M.; Tignor, S.K.; Allen, J. (Eds.) Cambridge University Press: New York, NY, USA, 2013.

2. Field, C.B.; Barros, V.R.; Stocker, T.F.; Qin, D.; Dokken, D.J.; Ebi, K.L.; Mastrandrea, M.D.; Mach, K.; Plattner, G.; Allen, S.; et al. Managing the Risks of Extreme Events and Disasters to Advance Climate Change Adaptation. In A Special Report of Working Groups I and II of the Intergovernmental Panel on Climate Change; Intergovernmental Panel on Climate Change: Geneva, Switzerland, 2012; pp. 1-594.

3. Smith, K.; Woodward, D.; Campbell-Lendrum, D.; Chadee, Y.; Honda, Y.; Liu, Q.; Olwoch, B.; Revich, B.; Sauerborn, R. Human health: Impacts, adaptation and co-benefits. In Climate Change 2014: Impacts, Adaptation and Vulnerability. Part A: Global and Sectoral Aspects. Contribution of Working Group II to the Fifth Assessment Report of the Intergovernmental Panel on Clima; Intergovernmental Panel on Climate Change: Geneva, Switzerland, 2014.

4. Murray, V.; Waite, T. Climate Change and Human Health-The Links to the UN Landmark Agreement on Disaster Risk Reduction. Atmosphere 2018, 9, 231. [CrossRef]

5. IPCC Summary for Policymakers. Global Warming of $1.5^{\circ} \mathrm{C}$; Intergovernmental Panel on Climate Change: Geneva, Switzerland, 2018.

6. Hajat, S.; Vardoulakis, S.; Heaviside, C.; Eggen, B. Climate change effects on human health: Projections of temperature-related mortality for the UK during the 2020s, 2050s and 2080s. J. Epidemiol. Community Health 2014, 68, 641-648. [CrossRef] [PubMed]

7. Heal, M.R.; Heaviside, C.; Doherty, R.M.; Vieno, M.; Stevenson, D.S.; Vardoulakis, S. Health burdens of surface ozone in the UK for a range of future scenarios. Environ. Int. 2013, 61, 36-44. [CrossRef] [PubMed]

8. Medlock, J.M.; Leach, S.A. Effect of climate change on vector-borne disease risk in the UK. Lancet. Infect. Dis. 2015, 15, 721-730. [CrossRef]

9. Patz, J.A.; Campbell-Lendrum, D.; Holloway, T.; Foley, J.A. Impact of regional climate change on human health. Nature 2005, 438, 310-317. [CrossRef] [PubMed]

10. Gasparrini, A.; Guo, Y.; Hashizume, M.; Lavigne, E.; Zanobetti, A.; Schwartz, J.; Tobias, A.; Tong, S.; Rocklöv, J.; Forsberg, B.; et al. Mortality risk attributable to high and low ambient temperature: A multicountry observational study. Lancet 2015, 386, 369-375. [CrossRef]

11. Health Protection Agency. Health Effects of Climate Change in the UK 2012; Health Protection Agency: London, UK, 2012.

12. Fleming, L.E.; Leonardi, G.S.; White, M.P.; Medlock, J.; Alcock, I.; Macintyre, H.L.; Maguire, K.; Nichols, G.; Wheeler, B.W.; Morris, G.; et al. Beyond climate change and health: Integrating broader environmental change and natural environments for public health protection and promotion in the UK. Atmosphere 2018, 9, 245. [CrossRef]

13. Nichols, G.; Lake, I.; Heaviside, C. Climate Change and Water-Related Infectious Diseases. Atmosphere 2018, 9, 385. [CrossRef]

14. McGregor, G.; Ebi, K. El Niño Southern Oscillation (ENSO) and Health: An Overview for Climate and Health Researchers. Atmosphere 2018, 9, 282. [CrossRef]

15. Vencloviene, J.; Braziene, A.; Zaltauskaite, J.; Dobozinskas, P. The Influence of the North Atlantic Oscillation Index on Emergency Ambulance Calls for Elevated Arterial Blood Pressure. Atmosphere 2018, 9, 294. [CrossRef]

16. Kinney, P. Temporal Trends in Heat-Related Mortality: Implications for Future Projections. Atmosphere 2018, 9, 409. [CrossRef]

17. Półrolniczak, M.; Tomczyk, M.A.; Kolendowicz, L. Thermal Conditions in the City of Poznan (Poland) during Selected Heat Waves. Atmosphere 2018, 9, 11. [CrossRef]

18. Tomczyk, A.; Półrolniczak, M.; Kolendowicz, L. Cold Waves in Poznań (Poland) and Thermal Conditions in the City during Selected Cold Waves. Atmosphere 2018, 9, 208. [CrossRef]

19. Muthers, S.; Laschewski, G.; Matzarakis, A.; Półrolniczak, M.; Tomczyk, M.A.; Kolendowicz, L.; Papadakis, G.; Chalabi, Z.; Thornes, J.; Taylor, J.; et al. The Summers 2003 and 2015 in South-West Germany: Heat Waves and Heat-Related Mortality in the Context of Climate Change. Atmosphere 2017, 8, 224. [CrossRef]

20. Dear, K. Modelling Productivity Loss from Heat Stress. Atmosphere 2018, 9, 286. [CrossRef] 
21. Orru, K.; Tillmann, M.; Ebi, K.; Orru, H. Making Administrative Systems Adaptive to Emerging Climate Change-Related Health Effects: Case of Estonia. Atmosphere 2018, 9, 221. [CrossRef]

22. Papadakis, G.; Chalabi, Z.; Thornes, J. Ambulance Service Resource Planning for Extreme Temperatures: Analysis of Ambulance 999 Calls during Episodes of Extreme Temperature in London, UK. Atmosphere 2018, 9, 182. [CrossRef]

23. Koopmans, S.; Ronda, R.; Steeneveld, G.-J.; Holtslag, A.; Klein Tank, A. Quantifying the Effect of Different Urban Planning Strategies on Heat Stress for Current and Future Climates in the Agglomeration of The Hague (The Netherlands). Atmosphere 2018, 9, 353. [CrossRef]

24. Taylor, J.; Symonds, P.; Wilkinson, P.; Heaviside, C.; Macintyre, H.; Davies, M.; Mavrogianni, A.; Hutchinson, E. Estimating the influence of housing energy efficiency and overheating adaptations on heat-related mortality in the West Midlands, UK. Atmosphere 2018, 9, 190. [CrossRef]

25. Haines, A.; McMichael, A.J.; Smith, K.R.; Roberts, I.; Woodcock, J.; Markandya, A.; Armstrong, B.G.; Campbell-Lendrum, D.; Dangour, A.D.; Davies, M.; et al. Public health benefits of strategies to reduce greenhouse-gas emissions: Overview and implications for policy makers. Lancet 2009, 374, 2104-2114. [CrossRef]

26. Gasparrini, A.; Guo, Y.; Sera, F.; Vicedo-Cabrera, A.M.; Huber, V.; Tong, S.; de Sousa Zanotti Stagliorio Coelho, M.; Nascimento Saldiva, P.H.; Lavigne, E.; Matus Correa, P.; et al. Projections of temperature-related excess mortality under climate change scenarios. Lancet Planet. Heal. 2017, 1, e360-e367. [CrossRef]

27. Costello, A.; Abbas, M.; Allen, A.; Ball, S.; Bell, S.; Bellamy, R.; Friel, S.; Groce, N.; Johnson, A.; Kett, M.; et al. Managing the health effects of climate change: Lancet and University College London Institute for Global Health Commission. Lancet 2009, 373, 1693-1733. [CrossRef]

(C) 2019 by the author. Licensee MDPI, Basel, Switzerland. This article is an open access article distributed under the terms and conditions of the Creative Commons Attribution (CC BY) license (http:/ / creativecommons.org/licenses/by/4.0/). 